\title{
MEDICAL AID TO THE DEVELOPING COUNTRIES
}

\begin{abstract}
$\mathrm{F}^{\mathrm{o}}$ OLLOWING on a conference held at the Royal College of Surgeons of England in 1961, a nominating committee formed an independent Working Party under the chairmanship of Sir Arthur Porritt, president of the Royal College of Surgeons, to consider at a professional level the methods by which British medicine can contribute to the development of medical science and the medical services in the developing countries, particularly those of the British Commonwealth. Discussion was chiefly confined to Africa, the Middle East and Asia. The members of the Working Party were eminent medical men, including those with experience of medical administration and medical practice overseas. Observers representing the Department of Technical Co-operation, the Ministry of Health and the Department of Health for Scotland attended the meetings.

The Report of the Working Party * contains a number of interesting observations and recommendations. Generally, it is considered that in comparison with other nations, particularly the United States and the U.S.S.R., Great Britain is falling behind in its contributions to the medical advance of the developing countries. Remembering the great work done by British medical pioneers overseas this is a sad reflexion. At the same time, it is believed. that the British medical profession can play a much greater part in helping these countries and that such help is genuinely desired by most of them. The best and most economical way to give this help is to raise the standards of medical teaching at their own teaching centres, and to train their own teachers, so that this central influence may permeate the whole of their medical systems.
\end{abstract}

The Report then discusses the following subjects: (1) Intake of overseas undergraduates for medical training in this country. No central body for admissions is recommended.

(2) Intake of overseas postgraduates for medical training and experience in Great Britain. It is recommended that overseas postgraduates seeking hospital posts in the National Health Service of Great Britain should, on arrival, undergo a short period of clinical assessment, on a voluntary basis, before allocation.

(3) The outflow of British medical graduates to the developing countries. The Report here deals with profes. sorial or senior visits, the value of overseas exporience for British medical postgraduates, secondments of registrars and lecturers for service overseas and financial aid.

(4) Medical aid in the fields of public health and rural medicine. On this subject the memorandum by Dr. E. T. C. Spooner, dean of the London School of Hygiene and Tropical Medicine (Appendix III), gives important and useful information.

(5) Medical aid in the fields of nursing, midwifery and other ancillary services.

In conclusion, hopes were expressed that the most urgent attention would be given to the proposals of the Working Party, and that temporary considerations of economy would not be allowed to delay the implementation of measures which become daily more necessary.

* Department of Technical Co-operation. Medical Aid to the Developing Countries: Report by a Working Party. Pp. vi 38 . (London: H.M.S.O.,
1962.) 2s. net.
With the completion of the Report, the Working Party handed over its task to a Medical Advisory Committee of the Department of Technical Co-operation.

In connexion with this important report it should be observed that for many years the question of medicel aid has been the concern of the British Postgraduate Medical School, the British Postgraduate Medical Federation, the British Council, British Medical Schools, British schools of tropical medicine, Government departments and other bodies, each and all of whom have contributed in various ways to promulgate medical knowledge overseas, and to provide facilities for undergraduate and postgraduate medical study in the United Kingdom for members of the British Commonwealth. To-day the problem has become more urgent and pressing. The proposals of the Working Party, the fruit of knowledge and experience, should help greatly to bring British medical aid on an extended and desirable scale to the developing countries.

\section{PLANT POLYPLOIDY AND MUTATION}

\section{Mutations and Polyploidy in Plant Breeding}

By Arne Hagberg and Erik Åkerberg. Pp. 150. (London, Melbourne, Toronto: Heinemann Educational Books Ltd., 1962.) $30 s$.

7THIS book is described as an introductory survey of the polyploidy and mutation research, and its practical results, with reference to the cytogenetic section of the Swedish Seed Association. It is written for plant breeders and others interested in applied genetics, though the authors hope it may be of some use to students of genetics and plant breeding. There are nine chapters and an introduction within the compass of 123 pages; an appendix of nine pages giving notes on a number of cultivated plants grown in Sweden; an appendix, which is a glossary of certain scientific terms, mainly cytological and genetic; and a short bibliography of 18 items.

Obviously, within such a small compass, and considering the number and potential scope of the chapters, it is necessary to choose the material very carefully, but the authors are well aware that it has not been possible to deal adequately with a great number of important considerations and state repeatedly that they cannot develop their treatment of particular subjects because of lack of space. This is a pity, and will undoubtedly prove frustrating to students; it would have been more satisfactory in planning this book to have allowed more space, or alternatively to have omitted certain parts. For example, one may question whether the elementary genetics need have been included, or whether the list of domestic plants and the glossary are particularly useful for this book. The list of domestic plants has some peculiar lapses, also, such as the inclusion of the broad bean undor Phaseolus vulgaris, and of mangels, rutabaga and turnip under Legumos.

Nevertheless, the book is valuable and interesting in giving a clear account of the Swedish work, because the Swedes have been responsible for more work on the utilization in plant breeding of induced polyploidy and induced mutations than the breeders in any other country. They have also co-ordinated research on the scientific aspects of cytogenetics of polyploidy and mutations with the breeding work, and the account given in this 